\title{
Barreiras sanitárias e sua contribuição à formação médica: um relato de experiência
}

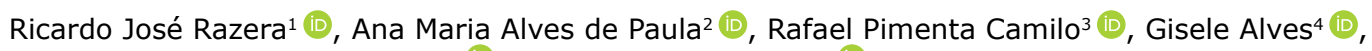
Ana Carolina Prioste de Oliveira ${ }^{5}$ (D), Danilo Borges Paulino ${ }^{(D)}$

\begin{abstract}
RESUMO
Introdução: Tendo em vista o enfrentamento da pandemia da COVID-19, em um município mineiro foram realizadas ações de Educação em Saúde em barreiras sanitárias, através da comunicação entre estudantes da saúde (principalmente estudantes de medicina) e a comunidade. Objetivo: Relatar a experiência de estudantes de Medicina em trabalho voluntário em barreiras sanitárias no contexto da pandemia de COVID-19 e refletir sobre sua contribuição para a formação médica. Método: Relato de experiência que reflete a atuação de dois estudantes de Medicina em barreiras sanitárias na cidade de Uberaba-MG, durante os meses de março e abril de 2020, em quatro oportunidades distintas. Nas ocasiões, foi avaliada a existência de sintomas no(a) motorista e nos(as) passageiros(as) e ações de prevenção e promoção da saúde foram compartilhadas. Posteriormente, foi elaborado o presente relato, refletindo com base na literatura sobre as potencialidades e limitações da vivência para a prática da Educação em Saúde e para a formação médica. Resultados: Identificou-se que foi possível edificar uma aprendizagem compartilhada entre diversas áreas da saúde e a população. Contribuiu-se, assim, para a sedimentação do conhecimento teórico dos estudantes através de uma prática interprofissional consoante às Diretrizes Curriculares Nacionais de 2014 para o curso de Medicina. Além disso, o conceito de "Educação em Saúde" foi contemplado a partir do empoderamento dos(as) cidadãos(ãs) alcançados(as) com a ação, especialmente em assuntos como higiene, isolamento social, acesso à saúde, principais sintomas, vacinação e, sobretudo, desconstrução de fake news, perfazendo uma dinâmica extremamente exitosa. Conclusão: A experiência contribuiu com a Educação em Saúde da população e com a formação dos(as) voluntários(as), principalmente estudantes de medicina, através do diálogo e da construção de saberes com responsabilidade social.
\end{abstract}

PALAVRAS-CHAVE: Infecções por coronavírus, Educação em saúde, Educação médica, Pandemias.

\section{INTRODUÇÃO}

Em dezembro de 2019, na cidade de Wuhan, China, surgiu um novo tipo de betacoronavírus, causador de uma síndrome respiratória aguda grave $^{1}$. Transmitido por gotículas respiratórias e aerossóis ${ }^{2}$, nos dois meses seguintes a doença do coronavírus 2019 (COVID-19) disseminou-se rapidamente por todo o país asiático, e no início de 2020, deixou suas fronteiras para chegar à Europa e às Américas ${ }^{3}$.

Em 11 de março, a Organização Mundial da Saúde (OMS) declarou a COVID-19 uma pande- $\mathrm{mia}^{4}$ (situação de transmissão sustentada de uma doença em diversos continentes simultaneamente $)^{5}$, iniciando então uma corrida mundial para a contenção da propagação viral. Como reação ao discurso do órgão, o Ministério da Saúde do Brasil (MS), através da portaria n. ${ }^{\circ} 356$ de 11 de março de 2020, estabeleceu medidas nacionais de isolamento social e parâmetros para a testagem de casos suspeitos ${ }^{6}$.

No âmbito local, alinhada às recomendações da OMS e do MS, a Prefeitura Municipal de Uberaba (PMU) em Minas Gerais, editou o Decreto n. ${ }^{\circ} 5.444$, de 06 de abril de 2020, que versou so-

\footnotetext{
${ }^{1}$ Faculdade de Medicina da Universidade Federal de Uberlândia.

2 Universidade Federal de Rondonópolis. Instituto de Ciências Exatas e Naturais. Curso de Medicina.

${ }^{3}$ Universidade de Uberaba. Instituto de Ciências Biológicas e da Saúde. Curso de Medicina.

${ }^{4}$ Faculdade de Medicina. Centro Universitário Atenas.

${ }^{5}$ Centro Universitário - Claretiano. Área da Saúde. Curso de Medicina.

${ }^{6}$ Universidade Federal de Uberlândia. Faculdade de Medicina. Departamento de Saúde Coletiva.
} 
bre o funcionamento facultativo de serviços considerados essenciais e suas regras de operação, bem como estabeleceu barreiras sanitárias na cidade. $\mathrm{O}$ artigo 13 do referido decreto também restringiu a chegada de pessoas por estradas e determinou o período de isolamento necessário na cidade para seus naturais e provenientes de viagens a localidades de alto risco, sob penalização, se descumprimento? ${ }^{7}$.

As barreiras sanitárias são mecanismos legais utilizados por autoridades sanitárias para controlar a circulação de pessoas, animais e plantas a fim de prevenir a disseminação de doenças nos locais sob suas atribulações ${ }^{8}$. São geralmente aplicadas ao comércio internacional de produtos agrícolas, tendo em vista o controle de alimentos e produtos exportados e consumidos internamente ${ }^{9}$, mas, no contexto da pandemia da COVID-19, as barreiras sanitárias tomaram outro caráter: foram estrategicamente localizadas no perímetro urbano das cidades e contaram com agentes de saúde e de trânsito para a vigilância de quem adentrava as fronteiras ${ }^{10}$. No caso de Uberaba, ainda tiveram o auxílio de estudantes de Medicina e de demais cursos das áreas da Saúde para aferição de temperatura corporal e esclarecimento de dúvidas dos(as) passageiros(as).

Nesse contexto, os(as) acadêmicos(as) tiveram a oportunidade de vivenciar na prática a Educação em Saúde, que é conceituada pelo MS como processo educativo de construção de conhecimento que contribui para aumentar a autonomia da população em seu próprio autocuidado e a fim de alcançar uma Atenção em Saúde de acordo com suas necessidades ${ }^{11}$. A Educação em Saúde é um pilar importante das ações dos órgãos públicos de saúde nesse momento de pandemia, já que a compreensão por parte da população sobre o tema é fundamental para o enfrentamento da doença. Assim sendo, a transmissão do novo coronavírus tem sua velocidade diminuída e diminuem-se os riscos de o sistema de saúde nacional entrar em colapso, o maior desafio enfrentado pelas autoridades médicas no momento ${ }^{12}$.

A Educação em Saúde é também um dos três eixos das Diretrizes Curriculares Nacionais (DCN) de 2014 para os cursos de graduação em Medicina no Brasil, que discorrem sobre as responsabilidades do(a) egresso em Medicina em sua própria formação, exigindo postura ativa do(a) acadêmico(a) e sua autonomia intelectual. Além disso, enfocam a importância da interação do(a) estudante com equipes multidisciplinares em campos de prática - onde se viabiliza a socialização do conhecimento com o grupo de trabalho e com a própria comunidade - para a aplicação de conteúdos teóricos em situações concretas ${ }^{13}$.

Assim, este manuscrito tem o objetivo de relatar a experiência de estudantes de Medicina em trabalho voluntário em barreiras sanitárias no contexto da pandemia de COVID-19.

\section{MÉTODO}

O presente trabalho enquadra-se como um relato de experiência e foi elaborado em duas etapas distintas. Em um primeiro momento, ocorreu a dinâmica das barreiras sanitárias, vivenciada por dois estudantes do curso de graduação em Medicina em quatro encontros diferentes durante os meses de abril e maio de 2020 na cidade de Uberaba-MG. Nas ocasiões, foi avaliada a existência de sintomas no(a) motorista e nos(as) passageiros(as) e ações de prevenção e promoção da saúde foram compartilhadas. Depois, em conjunto com os demais membros da equipe, foram construídas reflexões acerca da atividade em questão com base na literatura vigente, por busca em bases de dados pertinentes, tais como PubMed, SciELO e LILACS, e em sites oficiais de órgãos públicos. Foram tecidas, assim, considerações sobre as potencialidades e limitações da vivência para a prática da Educação em Saúde e para a formação médica. Por se enquadrar no item VIII do artigo primeiro da Resolução n. ${ }^{\circ} 510$ de 7 de abril de 2016 do Conselho Nacional de Saúde, este trabaIho não necessita de submissão ao Comitê de Ética em Pesquisa com Seres Humanos ${ }^{14}$.

\section{RELATO DE EXPERIÊNCIA}

A dinâmica das barreiras sanitárias ocorreu em Uberaba, município situado no interior do estado de Minas Gerais, na região do Triângulo Mineiro, com 295.998 habitantes, segundo o Censo de 2010 do Instituto Brasileiro de Geografia e Es- 
tatística (IBGE). A Secretaria Municipal de Saúde (SMS) estabeleceu as barreiras em pontos estratégicos da cidade onde o fluxo de veículos fosse intenso ou que funcionassem como porta de entrada para pessoas vindas de outras localidades. Foram abordados principalmente os veículos com pessoas de grupo de risco, como idosos ${ }^{15}$, os que somassem três pessoas ou mais, bem como carros com placas de municípios ulteriores.

Foram recrutados pela SMS dois guardas municipais para garantirem a segurança local, um guarda de trânsito para solicitar o estacionamento dos carros, um(a) colaborador(a) da SMS para inspeção e administração da barreira e dois/duas voluntários(as) para compartilharem as informações com os motoristas e demais passageiros dos veículos. Além disso, o local foi delimitado com cones e com uma tenda sinalizando os dizeres "barreira sanitária", equipada com mesas, cadeiras, termômetro corporal digital, panfletos, copos, água, lanche e equipamentos de proteção individual (EPIs), a saber: máscaras, aventais, luvas e álcool em gel.

Em se tratando especificamente dos(as) voluntários, esses(as) foram selecionados(as) através de contato com a SMS que, por sua vez, também realizou divulgação por chamadas televisivas e ligações telefônicas para estudantes da área da saúde. Os(as) voluntários(as) contavam com alunos(as) do curso de Medicina, os quais compõem este relato (Figura 1), e discentes de diferentes áreas do conhecimento, perfazendo um campo de atuação extremamente enriquecedor por seu caráter interdisciplinar. A formação dos(as) voluntários(as) para atuação nas barreiras sanitárias foi realizada pela SMS em um momento anterior à atuação, focando nos principais pontos a serem abordados e permitindo uma construção compartilhada e intersetorial ${ }^{16}$ de saberes entre profissionais de saúde, gestores(as) e estudantes.

Chegando ao local da atividade, a abordagem foi estabelecida da seguinte forma: em um primeiro instante, um(a) estudante se responsabilizou por aferir a temperatura de todas as pessoas que estavam dentro do veículo, informando-Ihes sobre como era realizada a aferição e o porquê de ser feita e, após obter o consentimento delas, a aferição era realizada e seu resultado comunicado a cada pessoa. Em seguida, outro(a) aluno(a) era responsável por questionar se algum(a) passageiro(a) havia apresentado sintomas de gripe nos últimos dias, especificando os sintomas típicos da síndrome gripal, como febre associada, principalmente, a tosse, dor de garganta ou dispneia ${ }^{15}$. Nesse momento, era enfatizado, ainda, o fato de todo caso de síndrome gripal estar sendo considerado suspeito de COVID-19. Em caso de resposta afirmativa, informava-se à pessoa sobre a importância de se isolar por, no mínimo, quatorze dias, sendo solicitada a assinatura de um termo de compromisso de isolamento - documento emitido pela prefeitura para registro interno e posterior acompanhamento da progressão da ocorrência.

Após esse procedimento, o(a) voluntário(a) compartilhava explicações, explanando sobre as circunstâncias nas quais a pessoa deveria permanecer em casa e observar seus sintomas ou procurar atendimento médico na Unidade Básica de Saúde (UBS) ou na Unidade de Pronto Atendimento (UPA), de acordo com sua sintomatologia. Panfletos contendo instruções sobre atendimento à população e sobre prevenção foram, então, entregues, destacando a importância do isolamento para evitar o colapso do sistema de saúde. É importante salientar que as informações foram compartilhadas também nas negativas sintomatológicas.

Para finalizar, perguntava-se se a pessoa desejaria sanar alguma dúvida, campo em que surgiram interrogações a respeito, por exemplo, da vacinação contra a gripe H1N1, que já estava sendo distribuída a idosos. Dois pontos desfavoráveis, no entanto, merecem destaque: provavelmente por se assemelhar a uma blitz policial, muitos se desviaram da parada e outros, mesmo atendendo ao pedido de estacionamento, mostraram-se muito apressados para interagir com os(as) profissionais da barreira sanitária, o que fazia com que o diálogo fosse conduzido de forma mais objetiva.

Embora algumas pessoas já demonstrassem ter conhecimento sobre a doença, o estado de pandemia, os cuidados de proteção e o momento de procurar os serviços de saúde, a ação dos(as) estudantes nessa barreira sanitária foi fundamental para desmistificar e reconstruir conceitos com a população. Sabe-se que a Educa- 
ção em Saúde, segundo Paulo Freire, deve ser uma construção compartilhada de conhecimento, estimulando com o(a) educando(a) a curiosidade, a capacidade crítica e a insubmissão ${ }^{17}$. Desse modo, pode-se afirmar que a dinâmica em questão atuou em consonância com o que preconiza também o Ministério da Saúde brasileiro, uma vez que promove o empoderamento com a busca ativa de possíveis pessoas em situação de risco e do processo de construção de saberes, a partir de um cenário em que a informação - nem sempre verídica - é facilmente disseminada, de forma que a autonomia do indivíduo fosse estimulada ${ }^{18}$.

Nesse sentido, em tempos em que as notícias falsas tomam cada vez mais espaço ${ }^{19}$, é importante que os(as) estudantes sejam incentivados(as) a atuar de forma horizontal, exercendo o papel de educadores(as) das pessoas e comunidades no cuidado em saúde. Ao compartilhar informações baseadas em evidências científicas para enfrentar uma pandemia como a do coronavírus, por exemplo, o(a) estudante esteve praticando a Educação em Saúde, sendo protagonista em sua formação, um aspecto formativo do(a) aluno(a) em relação ao exercício de seu trabalho ${ }^{18}$.

Além disso, o trabalho interdisciplinar com estudantes dos cursos de enfermagem, fisioterapia, psicologia, entre outros, auxiliou os(as) acadêmicos(as) de Medicina a ampliarem seus conhecimentos e seus horizontes para a construção de ações no âmbito da saúde, incluindo o enfrentamento da pandemia. Com as barreiras sanitárias, os(as) estudantes construíram saberes com as pessoas de forma contextualizada, permitindo que a curiosidade surgisse e, dessa forma, que uma nova aprendizagem fosse estabelecida a partir daquele ponto. ${ }^{8}$ Assim, as barreiras elucidam seu potencial pedagógico. À luz do princípio bioético da autonomia ${ }^{20}$, o empoderamento das pessoas foi possibilitado com essas práticas de Educação em Saúde, construindo com o outro os saberes necessários para que o indivíduo possa tomar parte nas tomadas de decisão sobre sua saúde e de sua comunidade.

Outro ponto sobre o qual a experiência com a barreira sanitária nos permitiu refletir foi o acesso à saúde das pessoas, ou seja, o exercício do direito à saúde ${ }^{21}$ através do uso adequado dos serviços de saúde ${ }^{22}$. Tendo em vista a época de pandemia, fez-se necessário alertar sobre qual nível de atenção recorrer quando em manifestação de sintomas, o que contemplou o diálogo sobre todas as dimensões que envolvem o acesso à saúde: as de ordem política, econômica, social, técnica, simbólica e, sobretudo, no que tange ao aspecto organizativo, que diz respeito à capacidade do serviço em responder às demandas dos usuários ${ }^{23}$. Essa ação contribuiu para a valorização da Atenção Primária em Saúde (APS), que garante a longitudinalidade e coordenação do cuidado na conjuntura a que se faz referência, assegurando um diagnóstico adiantado de casos graves ${ }^{15}$.

Por último, mas definitivamente não menos importante, faz-se necessário estabelecer um paralelo entre as barreiras sanitárias e a desconstrução das chamadas fake news. O conhecimento científico tem não apenas o desafio de dialogar com o conhecimento popular, mas também de desconstruir as notícias falsas, encontradas e compartilhadas em abundância na Internet ${ }^{24}$. 0 termo fake news se refere às informações sem autenticidade que são intencionalmente divulgadas com o intuito de enganar ${ }^{18}$, e, considerando a magnitude desse fenômeno, é fundamental investir mais em ações de Educação em Saúde com a comunidade. Nesse sentido, a ação da barreira sanitária contribuiu para enfrentar inverdades, uma vez que promoveu a aproximação entre a população e os estudantes da saúde, com a construção dos saberes necessários para enfrentamento responsável da COVID-19.

Considerando ainda a Internet como veículo de informações, é importante refletir sobre a desigualdade no acesso aos meios digitais, tendo em vista que a ação em saúde nos modos da barreira sanitária inclui as pessoas que não possuem acesso às notícias on-line ${ }^{25}$. Por outro aspecto, uma fragilidade da barreira foi abordar apenas as pessoas que possuem carro ou a possibilidade de ser passageiro(a) de um veículo automotor. No intuito de abarcar diferentes camadas sociais, seria ideal que os(as) estudantes e profissionais da saúde abordassem as pessoas em outros cenários onde vivem, com a devida atenção para as medidas de controle do contágio da doença. Além disso, é fundamental que essa ação das barreiras sanitárias se some a outras de Educação e Atenção à Saúde das 
pessoas, no enfrentamento desta pandemia e de outros agravos em saúde relevantes no contexto de cada comunidade/população.

Dessa maneira, pode-se afirmar que os aprendizados atinentes à ação deste relato concentram-se tanto no impulso dado ao(à) estudante para que ele(a) seja protagonista do seu processo de ensino-aprendizagem, quanto na prática de compartilhar saberes no caminho do empoderamento de uma população. Assim sendo, tais potencialidades despertadas pela experiência propiciaram a emergência de um espírito crítico que apreende a realidade e consegue contribuir para sua transformação, por atitudes que podem parecer simples, mas que trazem outro delineamento para a Educação em Saúde. Todavia, os desafios ainda se colocam e, além dos anteriormente citados, destacamos a necessidade de aproximar cada vez mais o conhecimento científico da população por métodos que sejam, de fato, eficazes.

\section{Figura 1}

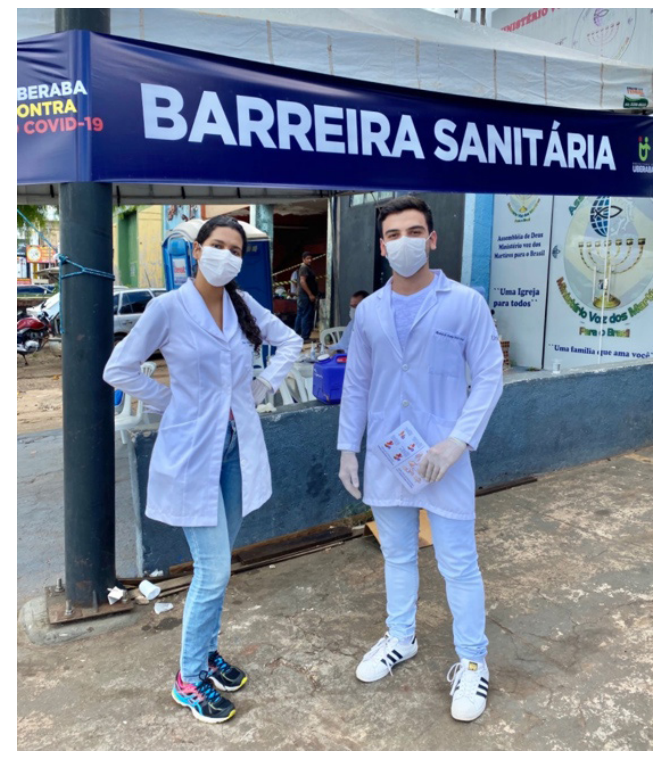

1 - Os estudantes Ana Maria Alves de Paula e Ricardo José Razera no primeiro dia da dinâmica das barreiras sanitárias, em março de 2020 na cidade de Uberaba-MG. Fonte: Autores

\section{CONCLUSÃO}

Com a experiência das barreiras sanitárias, os estudantes de medicina puderam perceber a importância de medidas de contenção no enfrentamento da pandemia de COVID-19. A presença de diferentes estudantes nesse cenário mostra a notabilidade de se trabalhar em uma equipe interprofissional, em prol da Saúde Pública. Além disso, esse exercício demonstra a necessidade de haver práticas de Educação em Saúde dialógicas e emancipadoras na formação e prática médicas.

Vale ressaltar, ainda, a necessidade das barreiras sanitárias no combate às notícias falsas relacionadas à COVID-19. A presença da desigualdade social existente dificulta o acesso a notícias verídicas e, consequentemente, sendo necessária a intervenção dos estudantes em relação à prática da Educação em Saúde, explicando de maneira acessível e didática para a população.

Com isso, é possível inferir que a atuação dos acadêmicos foi primordial para a Educação em Saúde da população ao oferecer condições básicas para que ela seja autônoma no processo de construção do seu saber em um momento de muitas notícias veiculadas, nem sempre verdadeiras. Simultaneamente, contribuíram para o crescimento intelectual e científico dos estudantes ao torná-los sujeitos ativos do próprio conhecimento, em consonância com o que preveem as DCN.

\section{REFERÊNCIAS}

1. Huang C, Wang Y, Li X, Ren L, Zhao J, Hu Y, et al. Clinical features of patients infected with 2019 novel coronavirus in Wuhan, China. Lancet [Internet]. 2020 [citado $16 \mathrm{Abr}$ 2020]; 497-506. Disponível em: https://www.thelancet. com/journals/lancet/article/PIIS0140-6736(20)301835/fulltext.

2. iatong S, Lanqin L, Wenjun L. COVID-19 epidemic: disease characteristics in children. J Med Virol [Internet]. 2020 [citado $16 \mathrm{Abr}$ 2020]; Disponível em: https://onlinelibrary.wiley.com/doi/full/10.1002/jmv.25807.

3. olsua $\mathrm{ML}$, DeBolt $\mathrm{C}$, Lindquist $\mathrm{S}$, Lofy $\mathrm{KH}$, Wiesman J, Bruce $\mathrm{H}$, et al. First case of 2019 Novel Coronavirus in the United States. N Engl J Med [Internet]. 2020 [citado 16 Abr 2020]; 929-936. Disponível em: https://www.nejm. org/doi/full/10.1056/NEJMoa2001191.

4. OMS afirma que COVID-19 é agora caracterizada como pandemia. 11 Mar 2020 [citado 16 Abr 2020]. In: Organização Pan-Americana da Saúde. Banco de Notícias [Internet]. Brasília: OPAS/OMS Brasil. Disponível em: https:// www.paho.org/bra/index.php?option=com_content\&view $=$ article $\&$ id $=6120$ : oms-afirma-que-covid-19-e-agora-caracterizada-como-pandemia\&Itemid $=812$ 
5. Schueler P. O que é uma pandemia. 31 Mar 2020 [citado 08 Mai 2020]. In: Fundação Oswaldo Cruz. Notícias e Artigos [Internet]. Manguinhos: Bio-Manguinhos/Fiocruz. Disponível em: https://www.bio.fiocruz.br/index.php/ br/noticias/1763-o-que-e-uma-pandemia

6. Portaria no 356 , de 11 de março de 2020. Dispõe sobre a regulamentação e operacionalização do disposto na Lei no 13.979 , de 6 de fevereiro de 2020, que estabelece as medidas para enfrentamento da emergência de saúde pública de importância internacional decorrente do coronavírus (COVID-19). Diário Oficial da União. Brasília, DF: Ministério da Saúde; Seção 1, 12 Mar 2020.

7. Decreto no 5.444 , de 06 de abril de 2020. Impõe, no âmbito do Município de Uberaba, Estado de Minas Gerais, medidas de proteção à coletividade a serem adotadas para enfrentamento da emergência de saúde pública de importância internacional decorrente do Coronavírus - COVID- 19 e dá outras providências. Porta Voz Uberaba no 1808. Uberaba, MG; 13 Abr 2020.

8. Veja a importância e como estão sendo feitas as barreiras sanitárias para o enfrentamento da Covid-19, na PB. 31 Mar 2020 [citado 02 Mai 2020]. In: PB AGORA. Saúde [internet]. João Pessoa: PB AGORA c2019. Disponível em: https://www.pbagora.com.br/noticia/ saude/qual-a-importancia-e-como-estao-sendo-feitas-as-barreiras-sanitarias-para-o-enfrentamento-ao-covid-19-na-pb/

9. Ministério das Relações Exteriores [Internet]. Brasília: Governo Federal; [citado 02 Mai 2020]. Barreiras Sanitárias e Fitossanitárias; Disponível em: http://www. itamaraty.gov.br/pt-BR/politica-externa/diplomacia-economica-comercial-e-financeira/15559-barreiras-sanitarias-e-fitossanitarias

10. Sousa C. Barreiras sanitárias abordaram quase $1,7 \mathrm{mi}$ carros na sexta-feira. 30 Mar 2020 [citado 02 Mai 2020]. In: Prefeitura de Uberaba. Notícias [Internet]. Uberaba: Prefeitura Municipal de Uberaba. Disponível em: http:// www.uberaba.mg.gov.br/portal/conteudo,49145

11. Brasil. Fundação Nacional de Saúde (Funasa). Diretrizes de educação em saúde visando à promoção da saúde: documento base - documento I/Fundação Nacional de Saúde. Brasília: Funasa, 2007.

12. Boletim Epidemiológico 08 [Internet]. Dispõe sobre a situação epidemiológica do país em relação à Covid-19 e sobre as orientações de diagnóstico e tratamento. Brasília, DF: Ministério da Saúde. [citado 02 Mai 2020]. Disponível em: https://www.saude.gov.br/images/ pdf/2020/April/09/be-covid-08-final-2.pdf

13. Resolução CNE/CES n³, de 20 de Junho de 2014. Institui diretrizes curriculares nacionais do curso de graduação em Medicina. Diário Oficial da União. Brasília, DF: Ministério da Educação; Seção 1, p.38, 20 Jun 2014.

14. Resolução n 510, de 7 de Abril de 2016. Diário Oficial da União. Brasília, DF: Conselho Nacional de Saúde; Seção 1, p. 44-6, 7 Abr 2016.

15. Protocolo de Manejo Clínico do Coronavírus (Covid-19) na Atenção Primária à saúde [Internet]. Brasília, DF: Ministé- rio da Saúde; p. 1-33, 2020. [citado 03 Mai 2020]. Disponível em: https://www.saude.gov.br/images/pdf/2020/ marco/20/20200318-ProtocoloManejo-ver002.pdf

16. Garcia LMT, Maio IG, Santos TI, Folha CBJC, Watanabe HAW. Intersetorialidade na saúde no Brasil no início do século XXI: um retrato das experiências. Saúde debate [Internet]. Dez 2014 [citado 01 Mai 2020]; 966-980. Disponível em: https://www.scielo.br/scielo.php?scrip$\mathrm{t}=\mathrm{sci}$ arttext\&pid=S0103=11042014000400966-\&/ngen https://doi.org/10.5935/0103-1104.20140083

17. Sevalho G. O conceito de vulnerabilidade e a educação em saúde fundamentada em Paulo Freire. Interface [Internet]. 2018 [citado 01 Mai 2020]; 177-188. Disponível em: https://www.scielo.br/scielo.php?script=sci_arttext\&pid=S1414-32832018000100177\&Ing=pt\&tIng =pt https://doi.org/10.1590/1807-57622016.0822

18. Falkenberg MB, Mendes TPL, Moraes EP, Souza EM. Educação em saúde e educação na saúde: conceitos e implicações para a saúde coletiva. Ciência \& Saúde Coletiva [Internet]. Mar 2014 [citado 15 Abr 2020]; 847-852. Disponível em: https://www.scielo.br/scielo.php?script=sci_arttext\&pid=S1413-81232014000300847\&Ing=en. https://doi.org/10.1590/1413-81232014193.01572013

19. Recuero R, Gruzd A. Cascatas de Fake News Políticas: um estudo de caso no Twitter. Galaxia (São Paulo, online) [Internet]. 2019 [citado 8 Mai 2020]; (41):31-47. Disponível em: https://www.scielo.br/scielo.php?scrip$\mathrm{t}=\mathrm{sci}$ arttext\&pid=S1982-25532019000200031 http:// dx.doi.org/10.1590/1982-25542019239035

20. Resolução CFM n 2217, de 27 de setembro de 2018. Código de Ética Médica. Brasília, DF: Conselho Federal de Medicina; 27 Set 2018.

21. Constituição (1988). Constituição da República Federativa do Brasil. Brasília, DF: Senado Federal; 1988.

22. Sanchez RM, Ciconelli RM. Conceitos de acesso à saúde. Rev Panam Salud Publica [Internet]. 2012 [citado 01 Mai 2020]; 260-268. Disponível em: https://www.scielosp.org/pdf/rpsp/2012.v31n3/260-268/pt

23. Assis MMA, Jesus WLA. Acesso aos serviços de saúde: abordagens, conceitos, políticas e modelo de análise. Ciência \& Saúde Coletiva [Internet]. Nov 2012 [citado 16 Abr 2020]; 2865-2875. Disponível em: https://www.scielo.br/scielo.php?script=sci_arttext\&pi$\mathrm{d}=\mathrm{S} 1413-81232012001100002 \& \mathrm{ng}=\mathrm{en}$. http://dx.doi. org/10.1590/S1413-81232012001100002

24. Waisbord, S. Fake health news in the new regime of truth and (mis)information. Rev Eletron Comun Inf Inov Saúde [Internet]. 2020 [citado em 16 Abr 2020]; 6-11. Disponível em: https://www.reciis.icict.fiocruz.br/index. $\mathrm{php} / \mathrm{reciis} /$ article/view/1953

25. Barreto PS, Amorim L, Garcia MP, Almeida C. Zika e microcefalia no Facebook da Fiocruz: a busca pelo diálogo com a população e a ação contra os boatos sobre a epidemia. Rev Eletron Comun Inf Inov Saúde [Internet]. 2020 [citado 16 Abr 2020]; 18-33. Disponível em: https://www.reciis.icict.fiocruz.br/index.php/reciis/article/view/1792 


\section{AGRADECIMENTOS}

Agradecemos à Prefeitura Municipal de Uberaba-MG pelo apoio nas barreiras sanitárias. Agradecemos à Secretaria Municipal de Saúde pela disponibilidade em ceder espaços físicos para a prática do projeto. Agradecemos também aos voluntários que participaram de forma ativa na execução dessa proposta. Agradecemos às pessoas que se disponibilizaram a dialogar com os voluntários presentes nas barreiras sanitárias.

\section{CONFLITO DE INTERESSES}

Os autores declaram não haver conflitos de interesses neste estudo.

\section{CONTRIBUIÇÃO DOS AUTORES}

Ana Maria Alves de Paula e Ricardo José Razera foram os partícipes da ação a partir da qual se desenvolveu o presente relato de experiência, contribuindo, também, em todas as etapas de elaboração do texto. Os demais autores contribuíram para a redação e revisão do manuscrito.

Autor Correspondente:

Ricardo José Razera

razeraricardo@gmail.com

Editor:

Prof. Dr Marcelo Riberto

Recebido: 10/07/2020

Aprovado: $27 / 11 / 2020$ 